\title{
Embolization of Bio-Alcamid Gluteal Injections in a Female Patient with Patent Foramen Ovale Leading to ARDS and Embolic Stroke
}

\author{
James Bolduc ${ }^{1}$, Beshoy Abdalla ${ }^{1} \mathbb{D}$, Mansoor Choudhry ${ }^{1}$, Muhammad Danial ${ }^{1}$ and \\ Syed A. A. Rizvi ${ }^{2 * *(D)}$ \\ 1 Dr. Kiran C. Patel College of Osteopathic Medicine, Nova Southeastern University, Fort Lauderdale, \\ FL 33314, USA; jb3646@mynsu.nova.edu (J.B.); ba501@mynsu.nova.edu (B.A.); \\ mc3231@mynsu.nova.edu (M.C.); md1325@mynsu.nova.edu (M.D.) \\ 2 School of Pharmacy, Hampton University, Hampton, VA 23668, USA \\ * Correspondence: syed.rizvi@hamptonu.edu; Tel.: +01-757-727-5455
}

Received: 22 July 2019; Accepted: 24 September 2019; Published: 26 September 2019

\begin{abstract}
Bio-Alcamid is a non-FDA approved permanent dermal filler with a few known adverse effects including granuloma formation at injection site, skin infections, abscess and painful inflammation. Embolization of Bio-Alcamid has not been reported and likely represents a very rare complication. We present the case of a thirty-one-year-old female who presents with cough, dyspnea, hemoptysis, fever, and pleuritic chest pain several hours after receiving Bio-Alcamid gluteal injections. The patient's symptoms progress rapidly and, within three days, she develops acute respiratory failure requiring intubation. A chest x-ray consistent with acute respiratory distress syndrome (ARDS) is viewed. Concurrently, a 2D echocardiogram reveals a patent foramen ovale (PFO) and severe pulmonary hypertension. Five weeks after initial presentation to the emergency department, the patient demonstrates flaccid quadriplegia, is poorly responsive when sedation is held, and her CT scan of the brain showed multifocal infarcts involving bilateral cerebral hemispheres. A CT of the abdomen reveals renal and splenic infarcts. This case study presents a rare complication of a nonbiodegradable dermal filler, Bio-Alcamid.
\end{abstract}

Keywords: bio-alcamid; dermal filler; acute respiratory distress syndrome; embolic stroke

\section{Introduction}

During the last few decades, as the use of cosmetic augmentation has become more prevalent, numerous cosmetic prostheses and dermal fillers have become available. According to the American Society for Aesthetic Plastic Surgery in 2012, the placement of dermal fillers is the second most commonly performed minimally invasive cosmetic procedure in the United States. Unfortunately, not all dermal fillers are approved by the United States Food and Drug Administration (FDA). Select dermal fillers are approved by the FDA for the purpose of correcting wrinkles, skin folds, and lipoatrophy. They are not approved, however, to be placed in the following anatomic regions: glutes, breasts, feet, bones, muscles, ligaments, and tendons. There are four types of absorbable dermal fillers approved by the FDA (Collagen, Hyaluronic acid, Calcium hydroxyapatite, Poly-L-lactic acid) and one type of non-absorbable dermal filler (Polymethylmethacrylate beads) [1,2].

Bio-Alcamid, (Polyalkylimide gel) the permanent dermal filling used in this case, is not currently FDA approved, but was once thought to be a safe water-based permanent dermal filler as it was being used worldwide. Bio-Alcamid was used mainly to treat a multitude of soft tissue defects and was used extensively in patients with HIV. Well-known complications of Bio-Alcamid have been documented in the literature, including granuloma formation at injection site [3], skin infections, abscesses and painful 
inflammation [4,5]. Embolization of Bio-Alcamid has not been reported yet, and likely represents a very rare complication [6]. A recent review article, covering the past ten years, lists many reported side effects of this filler [7].

\section{Case Presentation Section}

A thirty-one-year-old female (oral informed consent was obtained), with a past medical history of asthma and intermittent cocaine use, developed cough, dyspnea, hemoptysis, fever, and pleuritic chest pain several hours after receiving Bio-Alcamid gluteal injections. Despite a course of Levaquin, she required admission to her local community hospital. Initial workup at the hospital included a lower extremity doppler ultrasound, which was negative for deep vein thrombosis, and a CT without contrast that showed multiple bilateral areas of patchy infiltrates predominantly in the periphery. Occurring on day two of admission, a CT with contrast showed progressive worsening of the infiltrates, with development in the bilateral apices, and the superior and posterior left upper lobe (Figure 1a). Pulmonary artery enlargement, engorgement with redistribution of blood flow, and right-sided pleural effusion also was reported. A right-sided thoracentesis was performed.

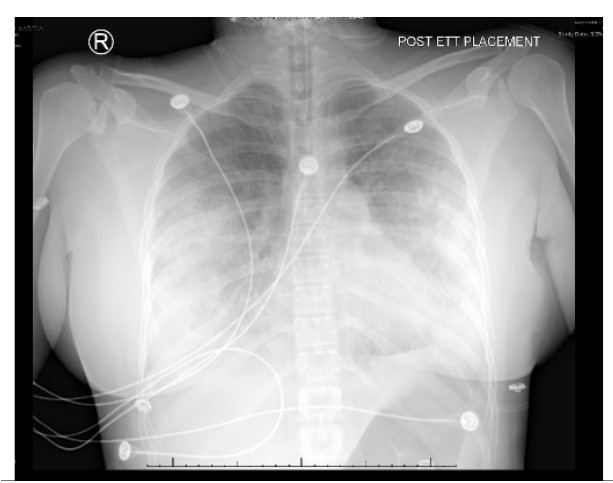

(a)

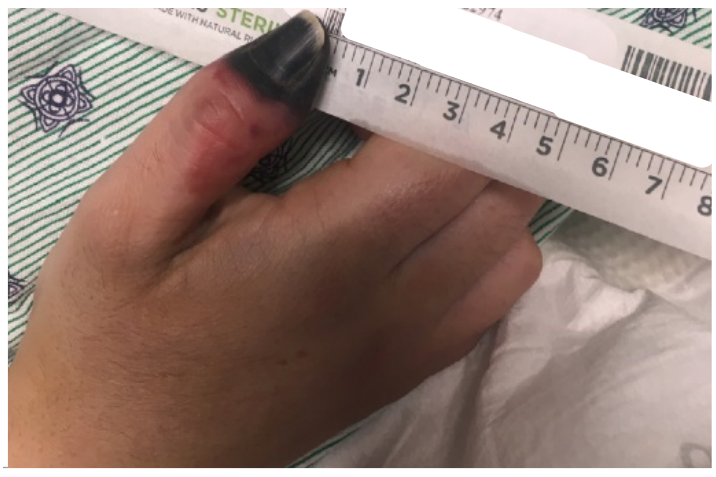

(b)

Figure 1. (a) Diffuse bilateral effusion- A/P view; (b) Right thumb dry gangrene.

The patient remained admitted and required intubation on day three. She was treated with high-dose steroids and antibiotics were broadened to linezolid, meropenem and levofloxacin. A work-up revealed a negative legionella urine antigen test, a negative test for tuberculosis, a negative hepatitis panel and a negative HIV screen. The patient was transferred on day five to a larger Level 1 trauma center with more resources for evaluation of Extracorporeal membrane oxygenation (ECMO). Physicians decided ECMO was not required., The patient, at the time of transfer, responded to Furosemide diuresis, bed proning, and nitric oxide with good response.

Upon arrival to the new facility, the patient was admitted to the Intensive Care Unit (ICU) and started on a Bumex drip and had a 2D-echocardiogram performed. The echocardiogram demonstrated a positive bubble study in the left atrium, suggesting a patent foramen ovale (PFO), severe pulmonary hypertension with a right ventricular mild dilation and reduced function. During the first three days of admission to the new hospital, the patient developed thrombosis of her right radial artery requiring a radial thrombectomy; she required a transfusion of one unit of packed red blood cells and one unit of platelets, plasmapheresis due to a possible TTP, and a Nicardipine (Cardene) drip. Dry gangrene in the distal right thumb developed due to a right radial artery thrombus (Figure 1b). The patient also demonstrated decreased responsiveness while on sedation vacation. A CT of the brain taken during this time reported multifocal acute infarcts involving the bilateral cerebral hemispheres and the left cerebellar hemisphere, given involvement of multiple vascular territories (Figure 2). A CT 
arteriogram of the brain and neck with IV contrast demonstrated an incomplete occlusive filling defect of the proximal internal jugular vein, raising concern for a partial thrombosis.

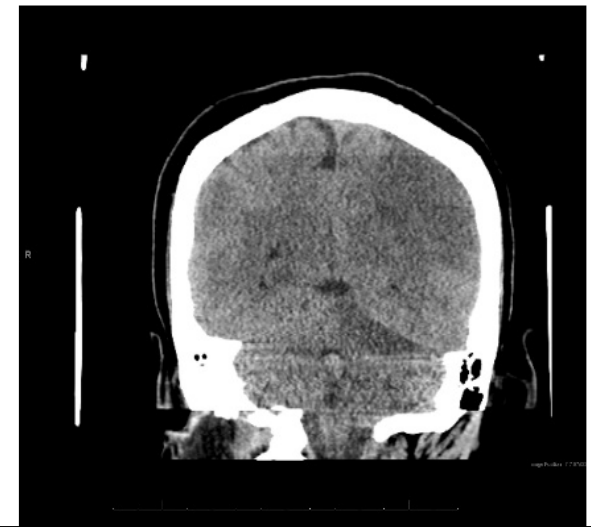

(a)

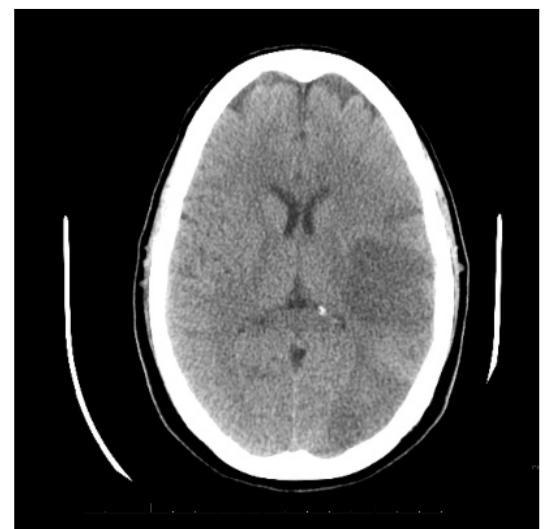

(b)

Figure 2. (a) Diffuse infarcts; (b) Temporal and occipital lobe infarcts.

The patient's hospital stay was complicated by disseminated intravascular coagulation on day eight of admission to the ICU. The patient underwent a tracheostomy with a Bivona tracheostomy tube \#8 for ongoing ventilator requirements on day nine of her stay. She developed a left pneumothorax on day 11 and a right pneumothorax on day 14, requiring bilateral chest tubes. The patient developed worsening bronchospasm and pneumothorax re-expansion on day 15. She was administered Nimbex, nitric oxide, and systemic steroids, while multi-drug-resistant Escherichia coli (E. coli) was cultured from urine. Her stay also was complicated by hypoxia, fever and increased white blood cell counts on days 22 and 23, which was addressed with antibiotics. A CT of the abdomen and pelvis at this time did not show any abscesses but did show evidence of infarcts in the kidney and spleen.

Four weeks after initial presentation to the emergency department, a neurocritical care evaluation reported the left posterior middle cerebral (MCA) and posterior cerebral (PCA) arteries, and right PCA and left superior cerebellar artery (SCA) infarcts. The report suggested severe encephalopathy. A CT angiogram of the head and neck showed no large vessel occlusion or significant steno-occlusive disease. Venous dopplers of the lower extremities was positive for a right external iliac vein non-occlusive deep vein thrombosis (DVT) for which she received an IVC filter. The patient had developed flaccid quadriplegia during hospitalization over the past month. She remains sedated on propofol and fentanyl and is poorly responsive when sedation is held.

\section{Discussion}

Generally, the use of Bio-Alcamid as a soft tissue filler has proven to be relatively free of adverse effects in the short term, with complications tending to surface several years after injection [8]. The vast majority of adverse effects associated with Bio-Alcamid is abscess formation [9,10], granulomas [3-5], infectious complications [11-13], and painful inflammatory nodules [5,14,15]. A late-onset gluteal abscess was reported in one case of Bio-Alcamid use in the buttocks muscle [4]. A literature review revealed no reported cases of Bio-Alcamid (Polyalkylimide gel) embolization though local migration of the substance as a complication [16]. Embolization of the permanent filler Bio-Alcamid, resulting in ARDS, is a radical manifestation not commonly observed in other cases of temporary dermal filler embolization. Though rare, embolization resulting in pulmonary embolism of other soft dermal fillers, such as polyacrylamide, resulting in death has been reported [17]. 
Gluteal injections of Polyacrylamide hydrogel were reported with similar presentation to this case report, which resulted in embolization and respiratory failure of the patient [18]. Alveolar hemorrhage after polyacrylamide injection for breast augmentation has also been noted [19]. The most commonly used dermal filler, hyaluronic acid, has been known to embolize, but the availability of hyaluronidase has prevented the prevalence of serious complications [6], though blindness has occurred due to occlusion of the retinal branch artery [20]. Regarding a previously unknown patent foramen ovale, the results were catastrophic for this patient, resulting in multiple cortical infarcts and severe encephalopathy. Her clinical course could have been much less severe, and likely would have spared her from anoxic brain injury if the patient had not had this congenital heart defect.

The severity and extent of this patients' embolization with a dermal filler has not been reported in any one patient at any one time, however. The Bio-Alcamid filler embolized diffusely throughout her lungs and, subsequently, to her brain, internal organs namely the kidneys and spleen, and even reached the peripheral circulation as evidenced by radial artery thrombosis resulting in thumb dry gangrene. The PFO seen in this patient elaborated the clinical consequences of embolization because it granted access for a paradoxical embolus to enter arterial circulation and into the brain vasculature. Even if this patient did not have this congenital heart defect, the morbidity caused by embolization proved to be much more diffuse and disastrous than evidenced by the reported complications in the literature.

A limitation of the case study is that the amount of Bio-Alcamid filler used in this patient is unknown. Bio-Alcamid is used most commonly for facial cosmetic procedures, though it has been used for breast procedures as well. The amount of Bio-Alcamid used in facial procedures tends to be in the $2-5$ cc range. It is unknown how much was used in this patient's gluteal injection, however, the use of other commonly used fillers or autologous fat transfers in the gluteal region usually involves 100-200 cc. The potential for adverse reactions increases with the amount of dermal filler used. It is likely that a large amount of Bio-Alcamid used for cosmetic purposes in the gluteus muscles increased the likelihood of an adverse event, like an embolization, occurring. Another limitation of the case study is that we do not know the exact anatomic distribution of the Bio-Alcamid injections in the gluteus muscles. The vascular supply of the gluteus muscles varies depending upon the region in question. Would application of these dermal fillers in more vascular regions of the gluteus muscles make embolization more likely? It is also worth mentioning that Bio-Alcamid injections usually are administered in subcutaneous adipose tissue; If the physician administered the injections into deeper tissues, that may have affected the risk profile of the dermal injections.

\section{Conclusions}

The embolization of the Bio-Alcamid reported in this case report represents an extremely rare possible complication, especially regarding cosmetic use in larger muscles or body parts that require larger volumes of application. The severity of the side effects should be considered by physicians who use Bio-Alcamid fillers for cosmetic purposes. The popularity of Bio-Alcamid has decreased greatly since the discovery of its many long-term complications, however, it is still used. This case report provides evidence of rare but devastating complications of which physicians should be aware. The possibility of such complications should dissuade physicians from using Bio-Alcamid for cosmetic procedures involving larger volumes of filler and larger body parts.

Author Contributions: Conception and design, J.B.; B.A.; M.C.; and M.D. writing-original draft preparation, M.D. and S.A.A.R.; writing-review and editing, M.D. and S.A.A.R.

Conflicts of Interest: The authors declare no conflict of interest.

\section{References}

1. Serra, M.S.; Gonçalves, L.Z. Permanent Fillers. In Botulinum Toxins, Fillers and Related Substances, 1st ed.; Issa, M.C.A., Tamura, B., Eds.; Springer International Publishing: Cham, Switzerland, 2017; pp. 1-8. 
2. US Food and Drug Administration. Available online: www.fda.gov/MedicalDevices/ucm2007470.htm\#hcp (accessed on 29 August 2018).

3. Akrish, S.; Dayan, D.; Taicher, S.; Adam, I.; Nagler, R.M. Foreign body granulomas after injection of Bio-alcamid for lip augmentation. Am. J. Otolaryngol. 2009, 30, 356-359. [CrossRef] [PubMed]

4. Campana, M.; Lazzeri, D.; Rosato, L.; Perello, R.; Vaccaro, M.; Ciappi, S.; Campa, A.; Brafa, A.; Nisi, G.; Brandi, C.; et al. Late-onset gluteal Escherichia coli abscess formation 7 years after soft tissue augmentation with Bio-Alcamid in a HIV-positive patient. J. Plast. Reconstr. Aesthet. Surg. 2010, 63, 709-7110. [CrossRef] [PubMed]

5. Hönig, J. Cheek augmentation with Bio-Alcamid in facial lipoatrophy in HIV seropositive patients. J. Craniofac. Surg. 2008, 19, 1085-1088. [CrossRef] [PubMed]

6. DeLorenzi, C. Complications of injectable fillers, part 2: Vascular complications. Aesthet. Surg. J. 2014, 34, 584-600. [CrossRef] [PubMed]

7. Rostom, M.; Brendling, L.; Stewart, K. Bio-Alcamid complications: A 10 year review. J. Plast. Reconstr. Aesthet. Surg. 2019, 72, 848-862. [CrossRef] [PubMed]

8. Schelke, L.W.; van den Elzen, H.J.; Canninga, M.; Neumann, M.H. Complications after treatment with polyalkylimide. Dermatol. Surg. 2009, 35, 1625-1628. [CrossRef] [PubMed]

9. García-Pacheco, S.A.; Blanco-Rivas, R.; Campos-García, S. Polyalkylimide filler in human immunodeficiency virus-associated facial lipodystrophy: Ophthalmic complications. Arch. Soc. Esp. Oftalmol. 2014, 89, 421-424. [CrossRef] [PubMed]

10. Schütz, P.; Ibrahim, H.H.; Hussain, S.S.; Ali, T.S.; El-Bassuoni, K.; Thomas, J. Infected facial tissue fillers: Case series and review of the literature. J. Oral Maxillofac. Surg. 2012, 70, 2403-2412. [CrossRef] [PubMed]

11. Goldan, O.; Georgiou, I.; Grabov-Nardini, G.; Regev, E.; Tessone, A.; Liran, A.; Haik, J.; Mendes, D.; Orenstein, A.; Winkler, E. Early and late complications after a nonabsorbable hydrogel polymer injection: A series of 14 patients and novel management. Dermatol. Surg. 2007, 33, 199-206. [CrossRef] [PubMed]

12. Alves, M.D.; Brites, C.; Sprinz, E. HIV-associated lipodystrophy: A review from a Brazilian perspective. Ther. Clin. Risk Manag. 2014, 10, 559-566.

13. Serrano, C.; Serrano, S. Delayed infection after Bio-alcamid implantation. Actas Dermosifiliogr. 2006, 97, 460-462. [CrossRef]

14. Gómez-de la Fuente, E.; Alvarez-Fernández, J.G.; Pinedo, F.; Naz, E.; Gamo, R.; Vicente-Martín, F.J.; López-Estebaranz, J.L. Cutaneous adverse reaction to Bio-Alcamid implant. Actas Dermosifiliogr. 2007, 98, 271-275. [CrossRef]

15. Chrastil-LaTowsky, B.; Wesley, N.O.; MacGregor, J.L.; Kaminer, M.S.; Arndt, K.A. Delayed Inflammatory Reaction to Bio-Alcamid Polyacrylamide Gel Used for Soft-Tissue Augmentation. Arch. Dermatol. 2009, 145, 1309-1312. [CrossRef] [PubMed]

16. Karim, R.B.; Hage, J.J.; van Rozelaar, L.; Lange, C.A.; Raaijmakers, J. Complications of polyalkylimide $4 \%$ injections (Bio-Alcamid): A report of 18 cases. J. Plast. Reconstr. Aesthet. Surg. 2006, 59, 1409-1414. [CrossRef] [PubMed]

17. Nadarajah, J.T.; Collins, M.; Raboud, J.; Su, D.; Rao, K.; Loutfy, M.R.; Walmsley, S. Infectious complications of Bio-Alcamid filler used for HIV-related facial lipoatrophy. Clin. Infect. Dis. 2012, 55, 1568-1574. [CrossRef] [PubMed]

18. Hirsch, R.J.; Cohen, J.L.; Carruthers, J.D. Successful management of an unusual presentation of impending necrosis following a hyaluronic acid injection embolus and a proposed algorithm for management with hyaluronidase. Dermatol. Surg. 2007, 33, 357-360. [PubMed]

19. Lim, J.H.; Lee, J.M.; Choi, S.H.; Nam, H.S.; Cho, J.H.; Ryu, J.S.; Kwak, S.M. Alveolar Hemorrhage after Polyacrylamide Injection for Breast Augmentation. Korean J. Med. 2015, 88, 438-441. [CrossRef]

20. Peter, S.; Mennel, S. Retinal branch artery occlusion following injection of hyaluronic acid (Restylane). Clin. Exp. Ophthalmol. 2006, 34, 363-364. [CrossRef] [PubMed]

(C) 2019 by the authors. Licensee MDPI, Basel, Switzerland. This article is an open access article distributed under the terms and conditions of the Creative Commons Attribution (CC BY) license (http://creativecommons.org/licenses/by/4.0/). 